\title{
La praxis de la delegación del voto en el Parlamento de Andalucía
}

\author{
Alberto Anguita Susi \\ Profesor Titular de Derecho Constitucional \\ (Universidad de Jaén)
}

\begin{abstract}
Sumario: I. Introducción. II. La regulación autonómica de la ausencia de los parlamentarios. III. La casuística de la delegación del voto en el Parlamento de Andalucía. 1. ¿Cabe la delegación del voto en el ámbito parlamentario autonómico? 2. Supuestos. 3. Alcance. 4. Procedimiento. IV. Conclusiones.
\end{abstract}

\section{INTRODUCCIÓN}

La ausencia de los diputados en las sesiones y votaciones parlamentarias, sobre todo sin son prolongadas en el tiempo, interfiere en el correcto funcionamiento y en la imagen pública de estas instituciones, de aquí la necesidad de regular los motivos y procedimientos para paliar dichas ausencias. Una regulación, en todo caso, que debe trascender la mera conciliación entre la vida familiar y laboral de los diputados, para adentrarse en la conformación de la voluntad de los parlamentos como órganos deliberantes y representativos de la voluntad popular.

En este sentido, la representación política ha pasado de ser una categoría "pasiva" o "estática", cuyo fin era justificar el poder establecido, a una "dinámica" o "activa", en virtud de la cual los ciudadanos tienen derecho a participar de manera efectiva en los asuntos públicos ${ }^{1}$. Este tránsito tiene como principal consecuencia la aparición de

1 Sobre la evolución del concepto de representación, resultan ilustrativos los siguientes trabajos: DE VEGA P., "Significado constitucional de la representación política", Revista de Estudios Políticos, n 44, 1985; ACOSTA SÁNCHEZ J., "La articulación entre representación, constitución y democracia", Revista de Estudios Políticos, nº 86, 1994; ABELLÁN A.M., "Notas sobre la evolución histórica del parlamento y de la representación política", Revista de Estudios Políticos, nº 92, 1996; CHUECA RODRÍGUEZ R., "Representación, elección y mandato: en torno a dos recientes monografias sobre el proceso representativo", Revista Española de Derecho Constitucional, n 38, 1993; y ARRUEGO RODRÍGUEZ G., Representación políticay derecho fundamental, CEPC, Madrid, 2005. 
un circuito de legitimación democrática bajo el cual los representantes deben actuar de acuerdo con los intereses de los representados ${ }^{2}$.

El art. 23 CE sólo puede satisfacerse si los representantes políticos participan de una manera efectiva y plena en todos aquellos trámites y procedimientos que sirven para que el órgano representativo al que pertenecen exteriorice su posición y, en definitiva, cumpla las funciones que tiene atribuidas. Para ello se requiere, como presupuesto lógico, la presencia activa de dichos representantes en las sesiones parlamentarias, tal y como prevé el art. 79.2 CE, a tenor del cual las Cámaras deben contar, para la adopción de acuerdos, con la "asistencia" de la mayoría de sus miembros (democracia representativa/parlamentaria presencial ${ }^{3}$.

La consecución de este objetivo, no obstante, puede verse truncado si los representantes políticos, por distintas circunstancias ${ }^{4}$, se ven imposibilitados para ejercer las funciones inherentes al ejercicio de su cargo ${ }^{5}$. Ante esta situación caben distintas soluciones, cuya viabilidad constitucional resulta dudosa, tal y como sucede

${ }^{2}$ El profesor GARRORENA MORALES lo ha expresado gráficamente con su habitual clarividencia: "en definitiva, hemos pasado del concepto $<<$ representación-ante-el poder $>>$ al concepto $<<$ representación-poder $>>$, lo que a la postre, supone que el término $<<$ representación $>>$ ha comenzado a cubrir como significante, en este segundo caso, una realidad sustancialmente distinta de la que cubría. Representar, ahora, no es $<<$ actuar ante $>>$, sino $<<$ estar por $>>$, esto es, no es actuar por nosotros ante el poder, sino estar por nosotros en el poder". (Representación política y Constitución democrática, Civitas, Madrid, 1991, p. 50). En este sentido, PRESNO LINERA sostiene que se trata de un instrumento establecido para asegurar la expresión de la representatividad política, lo que debe servir para modular y articular la libertad del representante en el ejercicio de sus funciones. "La sustitución temporal de los cargos políticos representativos", en La sustitución temporal de los representantes políticos, CEPC, Madrid, 2009. pp. 22 y 23).

${ }^{3}$ Así lo ha recordado también nuestro Tribunal Constitucional, que en el Auto 1227/1988, de 7 de noviembre, afirmaba que "la asistencia a las sesiones no es tan sólo un mero deber reglamentario, sino al tiempo un requisito inexcusable para el cumplimiento de la globalidad de las tareas parlamentarias". En términos más drásticos, el art. 86 del Reglamento del Congreso de los Diputados de 1834 disponía. "dos de los secretarios apuntarán los nombres de todos los procuradores presentes, leyendo uno de los secretarios en voz alta la lista, por si hubiese omitido alguno; después de cuya lectura no se admitirán a votar a los que entren de nuevo en el salón". En los actuales Reglamentos parlamentarios es común encontrar términos como los de "presencia", "puerta cerrada", "viva voz", "tribuna", "escaño", "asistencia", etc, que ponen de manifiesto un parlamentarismo de corte presencial. Sobre este aspecto, véase a FERNÁNDEZ RIVEIRA R.M ${ }^{\mathrm{a}}$, El voto parlamentario, CEPG, Madrid, 2003, pp.114 a 142.

${ }^{4}$ En este trabajo no se van a analizar las consecuencias disciplinarias de la ausencia injustificada de los parlamentarios, para lo cual pueden verse, entre otros estudios, los de DÍEZ LAGO P., "El deber de asistencia de los parlamentarios a las sesiones y el derecho al ejercicio del cargo (art. 23.2 CE)", Revista de las Cortes Generales, no 23, 1991; y DEL PINO CARAZO A., "La suspensión de los derechos de los parlamentarios", Corts. Anuario de Derecho Parlamentario, no 17, 2006.

5 Sobre este aspecto, resulta muy interesante la panorámica jurídica que ofrece el trabajo de GARCÍA-ESCUDERO MÁRQUEZ P., "Voto parlamentario no presencial y sustitución temporal de los parlamentarios", Corts. Anuario de Derecho Parlamentario, no 24, 2010. 
con la delegación del voto; una práctica que en el caso del Parlamento de Andalucía ha generado una prolija casuística.

\section{LA REGULACIÓN AUTONÓMICA DE LA AUSENCIA DE LOS PARLAMENTARIOS}

Antes de proceder al análisis de dicha casuística convendría hacer las siguientes consideraciones sobre la regulación autonómica de esta materia.

1. Pese a lo que dispone la Ley Orgánica 3/2007, de 22 de marzo, para la igualdad efectiva de mujeres y hombres, puede decirse que el fundamento y el origen de las distintas reformas reglamentarias aprobadas en los últimos años no es tanto satisfacer la conciliación entre la vida personal y familiar como evitar que la ausencia de los parlamentarios pueda alterar una votación de especial trascendencia (investidura, moción de censura y cuestión de confianza) ${ }^{6}$.

2. Las previsiones reglamentarias no sirven para solucionar las consecuencias derivadas de las ausencias, más o menos prolongadas, tales como el ejercicio del voto parlamentario y la participación de los representantes en los debates ${ }^{7}$. La votación sirve para exteriorizar la voluntad del representante, pero el seguimiento de los debates previos resulta imprescindible para modelar el sentido del voto ${ }^{8}$.

${ }^{6}$ En el debate que tuvo lugar en el Pleno del Parlamento de Andalucía el 25 de marzo de 2009, al objeto de la toma en consideración de la proposición de reforma del Reglamento del Parlamento para facilitar la votación en los casos de maternidad, paternidad y supuestos de enfermedad, presentada por el Grupo parlamentario socialista, salió a relucir este tema. Al respecto, la diputada Pérez Fernández, en representación del Grupo proponente afirmaba: “(...) parece lógico que el Reglamento de la Cámara sea capaz de adaptarse para que las causas de enfermedad o las bajas por maternidad o paternidad de algunos de los diputados o diputadas no supongan una alternación en la relación de fuerzas extraídas de la voluntad popular, extraídas de las urnas". En el mismo sentido, el representante de Izquierda Unida, Sr. García Rodríguez, manifestaba: "En definitiva, lo que aquí se trae no es solo algo para defender el derecho de la mujer a la maternidad, y del hombre a la paternidad, sino lo que se trae, el objetivo que persigue esta propuesta de ley es que en ningún momento la exigua mayoría que hay en esta Cámara se modifique por otras circunstancias". (Diario de Sesiones del Parlamento de Andalucía n ${ }^{\circ}$ 41, de 25 de marzo de 2009, pp. 8 y 10).

${ }^{7}$ Piénsese en los casos en los que se requieren varias votaciones sucesivas, tal y como sucede en ciertos trámites del procedimiento legislativo (enmiendas in voce y transaccionales) o en la aprobación de las proposiciones no de ley y de las resoluciones.

${ }^{8}$ La votación es la manifestación parlamentaria más personal dado que es el vehículo a través del cual cada parlamentario expone su voluntad. FERNÁNDEZ RIVEIRA llega a diferenciar dos conceptos: el voto, como expresión de la voluntad de un sujeto respecto de un determinado contenido y la votación que es el acto por el que se ejerce el voto (El voto parlamentario, op. cit., p. 9). 
3. Los supuestos contemplados por las distintas regulaciones autonómicas requieren ser concretados jurídicamente, a fin de establecer su ámbito y alcance práctico. En este sentido, algunos reglamentos parlamentarios difieren las posibles dudas interpretativas que puedan suscitarse a los acuerdos que adopten sobre el particular los respectivos órganos parlamentarios de gobierno ${ }^{9}$.

4. Asimismo, se observa una deficiente enumeración de los supuestos que pueden dar lugar a la ausencia parlamentaria. De esta forma, mientras que los distintos reglamentos parlamentarios hablan de permiso de maternidad o paternidad (derivado de embarazo, nacimiento o adopción), hospitalización, enfermedad, incapacidad y convalecencia, en otros países, como Francia $^{10}$, se autoriza a los parlamentarios a delegar su derecho al voto, en casos de enfermedad, accidente, suceso familiar grave, misión temporal encomendada por el Gobierno, cumplimiento del servicio militar, participación en trabajos de Asambleas Internacionales, estar ausente de la metrópoli y casos de fuerza mayor apreciados por las Mesas de las Cámaras ${ }^{11}$.

\section{LA GASUÍSTICA DE LA DELEGACIÓN DEL VOTO EN EL PARLAMENTO DE ANDALUGÍA}

\section{1. ¿Cabe la delegación de voto en el ámbito parlamentario autonómico?}

La delegación del voto, prevista en el art. 85, párrafos $5^{\circ}$ y $6^{\circ}$, del Reglamento del Parlamento de Andalucía (RPA), ha generado una prolija praxis pese a que el art. 79.3 CE señala que "el voto de senadores y diputados es personal e indelegable", una previsión que conecta con la prohibición expresa de mandato imperativo del art. 67.2 $\mathrm{CE}^{12}$.

${ }^{9}$ Algunos Reglamentos parlamentarios delegan en la Mesa la forma, tal y como sucede con los arts. 144, 94 y 84 de los Reglamentos parlamentarios de Extremadura, Canarias y Cataluña, respectivamente.

${ }^{10}$ Vid. art. 1 de la Ordenanza n ${ }^{\circ}$ 58-1066, de 7 de noviembre de 1958, analizado por MARTÍNEZ R., "Sobre algunas peculiaridades del status jurídico del parlamentario francés: delegación del voto y sustitución parlamentaria", Revista de las Cortes Generales, no 22, 1991, pp. 132 y 133; y ROUVILLOIS F., "Heurs et malheurs d'un principe: le vote personnel des députés", Revue du Droit Public, no 3, 1998.

${ }^{11} \mathrm{El}$ art. 23 del Reglamento del Senado de 1847 establecía: "Si algún senador tuviere que ausentarse para desempeñar alguna comisión de servicio público por orden del gobierno, o con motivo de su salud o intereses, lo participará por escrito al Senado para su conocimiento, con expresión del lugar a donde se dirigiere".

12 Esto lleva a TERRÓN MONTERO a señalar que si bien "la delegación permitida por la Constitución francesa supone una peculiaridad del parlamentarismo galo ajena a la tradición y modos que han regido en los textos constitucionales históricos de nuestro país, no parece que la misma tenga fácil acomodo en el conjunto de valores y principios que rigen el actual modelo parlamentario, sea estatal o autonómico". ("La ausencia temporal del diputado por motivos relevantes: posibles soluciones", AAVV 
La claridad de la regulación constitucional, que no admite excepción alguna, unida a la homogeneidad organizativa del sistema representativo a nivel territorial, supondría la inviabilidad de la delegación de voto en el ámbito parlamentario autonómico, aunque, según la STC 179/1989, no sea exigible que las Asambleas legislativas autonómicas deban adaptar su estructura, organización y funcionamiento al de las Cortes Generales.

En nuestra opinión, cada representante político es depositario de la voluntad que se manifiesta en el derecho a asistir y votar de forma individualizada a las correspondientes sesiones parlamentarias. De aquí que no tenga sentido que un parlamentario pueda, por delegación, no ya votar sino participar en los debates previos a la votación de un asunto, lo que constituye una "sustitución" en toda regla ${ }^{13}$.

No es factible que el mandato representativo que recibe de los electores un diputado pueda "desdoblarse" a la hora de ejercer su derecho al voto. La relevancia de la institución parlamentaria y la trascendencia jurídico-constitucional de las votaciones en sede parlamentaria justificarían, por tanto, la eliminación de la delegación del voto y, sobre todo, el uso desmedido o poco riguroso de la misma.

\section{Supuestos ${ }^{14}$}

El art. 85 RPA prevé dos supuestos de delegación: la paternidad o maternidad con ocasión de embarazo, nacimiento o adopción (párrafo $5^{\circ}$ ) y la enfermedad o incapacidad prolongada (párrafo $6^{\circ}$ ). La previsión de estos supuestos requiere ser concretada jurídicamente, a fin de establecer su alcance y contenido.

$\mathrm{Al}$ respecto cabe apuntar que "el embarazo, la maternidad en sí, no es una enfermedad, y no puede ser asimilado el embarazo o el parto reciente de una parlamentaria a estados de salud precaria o accidentes que requieran hospitalización" 15 .

(Coord. J. Cano Bueso)., El Parlamento de Andalucía. Órganos de extracción parlamentaria. Órganos consultivos o de participación de designación parlamentaria, Jornadas de Estudio Organizadas por el Parlamento de Andalucía, XX Aniversario del Estatuto, Comares, Granada, 2004. p. 181).

${ }^{13}$ En este sentido resulta ilustrativo el artículo 85.1 del RPA, conforme al cual: "Los acuerdos serán válidos cuando hayan sido aprobados por la mayoría de los miembros presentes del órgano correspondiente, computándose, a tal efecto, los ausentes que hayan delegado su voto reglamentariamente cuando se encuentre presente el miembro de la Cámara en quien se haya producido la delegación" (la cursiva es añadida).

14 TERRÓN MONTERO J., "La delegación de voto en el ámbito parlamentario", AAVV (Coord. Pau i Vall F.)., Parlamento y Diputado, Jornadas de la Asociación de Letrados de Parlamentos, Tecnos, Madrid, 2011.

15 MARTÍN VIDA Ma.A. y JERÓNIMO SÁNCHEZ-BEATO E., "La votación pública por llamamiento de las parlamentarias andaluzas en los supuestos de embarazo o parto reciente (Comentario al artículo 86.2 del Reglamento del Parlamento andaluz)", en AAVV (Coord. J. Cano Bueso), El Parlamento 
De la misma forma sería oportuno precisar si la maternidad abarca un avanzado estado de gestión, las complicaciones derivadas de ésta o la proximidad del parto, haya hospitalización o no, así como las situaciones derivadas del permiso de maternidad o paternidad, que en sí mismas consideradas no suponen para el diputado un impedimento médico y personal.

Además, no todos los embarazos resultan problemáticos desde el punto de vista clínico, ni las posibles complicaciones tienen porqué darse durante el período de gestación. De hecho, será el facultativo quien deba valorar si la embarazada puede realizar desplazamientos o no, a los que los diputados están obligados para el cumplimiento efectivo y presencial de sus obligaciones. Lo mismo puede decirse del periodo de lactancia posterior al parto, que no es un periodo de incapacitación médica.

Desde el punto de vista práctico, las situaciones de enfermedad o incapacidad a la hora de solicitar y conceder la delegación de voto ha sido el aspecto que mayor problemática y casuística ha generado. En este sentido, la Comisión del Estatuto de los Diputado del Parlamento de Andalucía advertía "sobre la necesidad de una interpretación rigurosa y finalista del artículo 85 del Reglamento de la Cámara en tanto su número 6 parece estar pensado, dada su redacción, para los supuestos de imposibilidad médica de cierta entidad, no para meras contrariedades o incidencias. La línea de distinción es ciertamente difícil, pero recomendamos la necesidad de precisarla, incluso por esta propia Comisión a la vista del peligro de desnaturalización de los institutos jurídicos, que se podrían derivar de una interpretación demasiada laxa o poco depurada"16.

Teniendo en cuenta esta advertencia, parece claro que no procederá la delegación del voto durante los tratamientos clínicos comunes o los procesos de rehabilitación y convalecencia, quedando justificado su uso, en cambio, en procesos oncológicos, accidentes graves y cirugía mayor. Por ello, resulta inadmisible que se concedan delegaciones de voto, por ejemplo, porque el diputado/a tenga concertada una cita o prueba médica ${ }^{17}$.

\section{Alcance}

La delegación debe contener qué margen de maniobra tendría el parlamentario

de Andalucía.., op. cit. p. 216. En el mismo sentido puede verse a AGUILÓ I LÚCIA L., "Los permisos parentales de diputadas y diputados", AAVV., La democracia constitucional. Estudios en homenaje al profesor Francisco Rubio Llorente, Editores Varios, Madrid, 2002, p. 974.

${ }_{16}$ Boletín Oficial del Parlamento de Andalucía (BOPA) nº 131, de 26 de diciembre de 2012, p. 5.

${ }_{17} B O P A$ n $^{\circ} 88$, de 13 de octubre de 2015, p. 40 y n 74 , de 22 de septiembre de 2015, p. 50. 
delegado a la hora de ejercer las funciones propias de su cargo, especialmente en lo que se refiere a las votaciones y debates en los que podría participar "porque a toda decisión también debe precederle el debate y la dialéctica parlamentaria"18. En este sentido, el art. 85.5 debería hablar de "debate y votación", a efectos de evitar que una delegación sea utilizada por un parlamentario de forma reiterada o abusiva.

En cuanto al alcance temporal de la delegación, suele ser cláusula común que la delegación se conceda "durante todo el tiempo que pudiera imposibilitar dichas circunstancias el normal cumplimiento del ejercicio de las funciones derivadas del cargo" "19. Es decir, son frecuentes las delegaciones sine die, con las consiguientes disfuncionalidades que podrían derivarse de esta práctica ${ }^{20}$, consentida por la propia Comisión del Estatuto de los Diputados, en uno de cuyos dictámenes puede leerse que "de persistir su situación de prolongada enfermedad, para posteriores supuestos bastará con escrito de la interesada a la Mesa de la Cámara, que entenderá evacuado el dictamen favorable de esta Comisión, sin necesidad de reunión expresa de la misma, cuando previamente notificada la solicitud por los cauces reglamentarios no se manifieste indicación contraria con anterioridad a la sesión correspondiente del Pleno" ${ }^{21}$.

La delegación no debería extenderse en el tiempo más que lo estrictamente necesario, pese que el RPA permita la delegación durante un determinado periodo (enfermedad o incapacidad prolongada). De lo contrario se estaría propiciando la sustitución del mandato representativo por el mandato de partido, habida cuenta que "los votos delegados y su sentido quedarían en manos de la disciplina del jefe del grupo parlamentario correspondiente" ${ }^{\text {"22 }}$.

La delegación debe servir, por tanto, para paliar ausencias puntuales, debiéndose articular otros mecanismos en los casos de ausencias prolongadas, tales como la sustitución del parlamentario ausente por el siguiente candidato del mismo sexo que figura en la lista electoral.

${ }^{18}$ DE MIGUEL BÁRCENA J., "La personalidad e indelegabilidad del voto y las reformas de los Reglamentos de los Parlamentos Autonómicos", Revista Española de Derecho Constitucional, no 90, 2010, p. 152.

${ }^{19}$ BOPA n $\mathrm{n}^{\circ} 585$, de 21 de diciembre de 2010, p. 36 y n $^{\circ} 659$, de 14 de abril de 2011, p. 5.

${ }^{20}$ En un caso concreto la Mesa del Parlamento concedió una delegación de voto a favor de una diputada "para todas las votaciones que se generen en las sesiones plenarias que se celebren desde el 16 de mayo hasta el 20 de julio de 2014" (BOPA n ${ }^{\circ} 473$, de 13 de junio de 2014, p. 66). Un caso similar puede consultarse en el BOPA $\mathrm{n}^{\circ} 48$, de 31 de julio de 2015, p. 9.

${ }^{21} B O P A \mathrm{n}^{\circ} 105$, de 15 de noviembre de 2012, p. 12; n 131 , de 26 de diciembre de 2012, p. 5 y n 315 , de 17 de octubre de 2013, p. 24.

${ }^{22}$ DE MIGUEL BÁRCENA J., "El camino hacia la normalización política en el País Vasco", Revista General de Derecho Constitucional, nº 9, 2010, p. 12. 


\section{Procedimiento}

El art. 85.5 RPA dispone que en los casos de paternidad o maternidad, el procedimiento es reglado y no cabe apreciación alguna por la Mesa del Parlamento, que se limitará a verificar el supuesto de hecho y a conceder la delegación. En cuanto a los requisitos formales para proceder a la delegación ésta debe hacerse por escrito dirigido a dicho órgano, en el que constará el nombre del parlamentario delegado, los debates y votaciones a los que se extiende la delegación y la duración de ésta.

El art. 85.6 del RPA, por su parte, en casos de enfermedad o incapacidad prolongada, concede un importante margen de apreciación al Parlamento dado que tras la recepción de la propuesta por la Mesa ésta deberá elaborar unos criterios generales para determinar los supuestos de la delegación, y será el Pleno quien se pronuncie, previo dictamen de la Comisión del Estatuto de los Diputados, sobre las circunstancias que concurren en cada caso.

En la práctica, sin embargo, ni la Mesa ha elaborado aún dichos criterios, que aportarían un mayor grado de seguridad jurídica, ni la Comisión fundamenta de una manera adecuada sus decisiones, debido a la banalización y ligereza que rige la concesión de las delegaciones de voto. Una situación que no favorece, precisamente, la imagen pública de la institución parlamentaria.

Tampoco se mencionan los requisitos formales que requiere la delegación en dichos casos, por lo que habrá que entender que se exigen los previstos en el art. 85.5 del RPA, a los que habría que añadir la presentación de la documentación que acredite los motivos de la delegación. En este sentido, la práctica parlamentaria no es rigurosa ni formalista, como se acaba de apuntar, hasta el punto de que se han concedido delegaciones de voto en casos de enfermedad "cuya naturaleza y características son suficientemente conocidas" 23 , basándose en exclusiva en la manifestación del parlamentario delegante ${ }^{24} \mathrm{o}$ exigiéndose que se aporte "la correspondiente certificación de carácter médico" ${ }^{25}$.

${ }^{23}$ BOPA n n $^{2} 38$, de 11 de octubre de 2010, p. 26.

${ }^{24}$ BOPA n ${ }^{\circ} 97$, de 5 de noviembre de 2010.

${ }_{25}$ BOPA n ${ }^{\circ} 650$, de 1 de abril de 2011, p. 37. Curiosamente, se han dado situaciones que podemos calificar como "mixtas", en las que se exige certificado médico pero la Comisión se atiene al testimonio de una compañera de Grupo parlamentario $\left(B O P A \mathrm{n}^{\circ} 311\right.$, de 11 de octubre de 2013, y n 229 , de 24 de mayo de 2013). 


\section{GONGLUSIONES}

1. La conciliación entre la vida personal y el ejercicio del cargo representativo podría conseguirse mediante la extensión al ámbito parlamentario del conjunto de "prestaciones que se reconocen como derechos a cualquier trabajador, entre ellas las relacionadas con las situaciones de embarazo o parto (bajas por maternidad, fundamentalmente)"26. Sin embargo, entendemos que no cabe asimilar el cargo representativo con una relación laboral, en la medida que "las relaciones entre los parlamentos y sus componentes pertenecen al ámbito del derecho público o administrativo, y no al laboral" 27 . Sin olvidar que la flexibilidad del ejercicio del cargo representativo permitiría sin mayor dificultad conciliar la vida personal-familiar y laboral de los diputados.

2. La delegación está más encaminada a favorecer la conformación de las mayorías parlamentarias que coyunturalmente se formen en cada momento, por lo que no sirve para situaciones de ausencia prolongada, a las que convendrá dar una solución específica. La ausencia puntual de sus señorías no deja de ser una práctica hasta cierto punto habitual y soportable dado que, en principio, no obstaculiza la capacidad decisoria de los parlamentos.

3. La publicación por los órganos parlamentarios competentes de una serie de criterios estables a la hora de conceder una delegación, no sólo evitaría uso desviado de esta figura sino que concienciaría a los diputados de la especificidad y relevancia institucional del ejercicio del cargo que ostentan.

El derecho-deber de voto, y el de asistir previamente a los debates, contribuyen a conformar la voluntad de la Cámara a través del acuerdo personalizado de todos y cada uno de los parlamentarios, de ahí que la delegación de voto podría ser considerada una quiebra del mandato representativo.

${ }^{26}$ Cfr. MARTÍN VIDA M .A. y JERÓNIMO SÁNCHEZ-BEATO E., "La votación pública por llamamiento de las parlamentarias andaluzas en los supuestos de embarazo o parto reciente...", op. cit., p. 224

${ }^{27}$ DE MIGUEL BÁRCENA J., "El camino hacia la normalización política en el País Vasco", op. cit., p. 11. 